\title{
Operating Rooms Scheduling Using Tabu Search for Elective Surgeries in a Hospital Affected By War-Related Incidents
}

\author{
HUSSEIN HASAN ALI \\ Operation Management department, Middle Technical University / Baghdad \\ Email: hussain_ha2003@yahoo.com \\ Tel: 00601139070324/009647713351395
}

HENDRIK LAMSALI

School of Technology Management and Logistics UUM

Email: hendrik@uum.edu.my

Tel: 0060134878748

\section{SITI NOREZAM OTHMAN}

School of Technology Management and Logistics UUM

Email: norezam@uum.edu.my

\begin{abstract}
Hospital scheduling presents huge challenges for the healthcare industry. Various studies have been conducted in many different countries with focus on both elective and non-elective surgeries. There are important variables and factors that need to be taken into considerations. Different methods and approaches have also been used to examine hospital scheduling. Notwithstanding the continuous changes in modern healthcare services and hospital operations, consistent reviews and further studies are still required. The importance of hospital scheduling, particularly, has become more critical as the trade-off between limited resources and overwhelming demand is becoming more evident. This situation is even more pressing in a volatile country where shootings and bombings in public areas happened. Hospital scheduling for elective surgeries in volatile country such as Iraq is often interrupted by non-elective surgeries due to war-related incidents. Hence, this paper intends to address this issue by proposing a hospital scheduling model with focus on neurosurgery department. The aim of the model is to maximize utilization of operating room while concurrently minimizing idle time of surgery. The study focused on neurosurgery department in Al-Shahid Ghazi Al-Hariri hospital in Baghdad, Iraq. In doing so, Tabu search (TS) approach is applied where interruptions of non-elective surgery are incorporated into the main elective surgery-based model. Computational experiment is then carried out to test the model. The result indicates that the model is feasible and can be solved in reasonable times. Nonetheless, its feasibility is further tested as the problems size and the computation times is getting bigger and longer. Application of heuristic methods is the way forward to ensure better practicality of the proposed model. In the end, the potential benefit of this study and the proposed model is discussed.
\end{abstract}

Keywords: Operating Room Scheduling, Tabu Search, Mixed Integer Linear Programming, Elective Surgery. 


\section{Introduction}

Scheduling in general is responsible for the allocation of available production resources over time to meet a set of performance criteria (Soon \& School, 1997). Nowadays, scheduling healthcare sector be very important from two side. First: high cost spent in this sector and second the management want to maximize customer satisfaction and this will lead to increase the revenue (Cardoen, Demeulemeester, \& Beliën, 2010). In general, all manager in any hospital and during planning and scheduling operating rooms work to assigned one patient to the right operating room in the right time and assigned the right surgeon and staff to this room too and this is the main objective for each operating room scheduling (Lim, Mobasher, Bard, \& Najjarbashi, 2016). After that starting to solve other problems related to increase the utilization of operating room, maximize the productivity, minimize the idle time, waiting time...etc (Lehtonen, Torkki, Peltokorpi, \& Moilanen, 2013 \& Aringhieri, Landa, Soriano, Tànfani, \& Testi, 2015). The objective of this paper is to find ways to utilize operating room for elective surgery in neurosurgery department in which non-elective surgery due to war-related incidents were also considered. In a nutshell, the study intends to examine the potential impact of war-related incidents in a volatile country like Iraq towards utilization of elective surgeries. The case is Al-Shahid Ghazi Al-Hariri Hospital in Baghdad, Iraq. In this paper we proposed a tabu search model where the aims are to maximize utilization of operating rooms to minimize potential idle time. After that comparing the results with other results collected by using another approach MILP then measure the gap between the two models. The remaining part of this paper is organized as follows. In Section 2 literature review related to TS is presented. Section 3 showed TS elements while section 4 depicts the problem description followed by Section 5 on the proposed model formulation. Sections 6 focus on the computational experiments and Section 7 concludes the study.

\section{Literature Review}

This method was proposed by Glover in 1986 (Fred Glover, 1986). The basic ideas of this method were also placed by researchers Hansen and Jumard in 1988 (Hansen \& Jaumard, 1990). The final version of TS was drafted in 1989 by De Werra and Hertz(de Werra \& Hertz, 1989).TS is a very important approach working to change the ability of researchers to find solution to problems of practice significance. This application has been applied and shown results and solution to problem related to scheduling, designing, location and allocation logic and artificial intelligence, technology, communications, production, inventory, investment, routing and general combinational optimization (Fred Glover \& Laguna, 1997).

TS has ability to move through different local optima in the solution space with the help of its memory functions (Shahvari \& Logendran, 2017a). TS is a neighbourhood exploration technique introduced by Fred Glover in 1986. It is used to solve combinatorial optimization problems. TS principle work is working mode is a classical local search process, by visiting all neighbour solutions and starting to perform simple movement from the current solution. The application works to find the better solution by searching in neighbourhood. It is starts from initial solution randomly set. when TS find the better solution then the current point is updated, and the process is repeated until no improvement is possible. TS depend on tabu list to store the moves performed in previous iterations to avoid cycling moves (Ponsich \& Coello Coello, 2013a). By using lists, TS allows the acceptance of non-improved solutions. In addition, the algorithms return to apply the first neighbourhood again when the largest possible number of non-improved moves are attained (Demeester, Souffriau, De Causmaecker, \& Vanden Berghe, 2010). TS generate a short-term memory to save the information about the past step of search. This information will use to generate and exploit the better solutions and long term memory for rather the frequency of their occurrence over a longer period (Fred Glover \& Laguna, 1997). TS algorithms helps to avoid falling into the local optimal solution itself by relying on a list of TS (Xu, Yanpeng, \& Xuan, 2013). The widespread use of this method in different areas was a result of the advantages of TS which are non-complex, simple, characterised by flexibility and offer good quality solutions (D1az \& Fernández, 2001). 
The Tabu algorithm is used to find multiple solutions to various problems. Other researchers have used TS to find solutions for job-shop scheduling problems by reducing the make-span time and tardiness (Amaral Armentano \& Rigão Scrich, 2000;Nowicki \& Smutnicki, 2005);(Thamilselvan \& Balasubramanie, 2009). Other studies have used TS algorithms to find solutions for vehicle-routing problems (Cordeau \& Laporte, 2005;Jean-François Cordeau \& Maischberger, 2012; J-F Cordeau, Laporte, \& Mercier, 2001).

Some researchers have used the TS to find solutions for operating room scheduling problems. Dowsland(1998)used TS for nursing scheduling and focused on the development of an algorithm. It had the ability to provide sufficient number of nurses to the operating rooms at the right time without any delay. Saremi et al. (2013) used three simulation methods including TS to solve outpatient scheduling problems. They proposed algorithms to decrease waiting time for the patient reduce make-span and minimise the number of surgery cancellations. Niu, Peng, and ElMekkawy (2013)also used TS and focused on increasing the utilisation of operating rooms by providing adequate resources (doctors, nurses and materials). This minimised the total waiting time for patients along with the total completion time of surgeries. TS work according to the next flowchart.

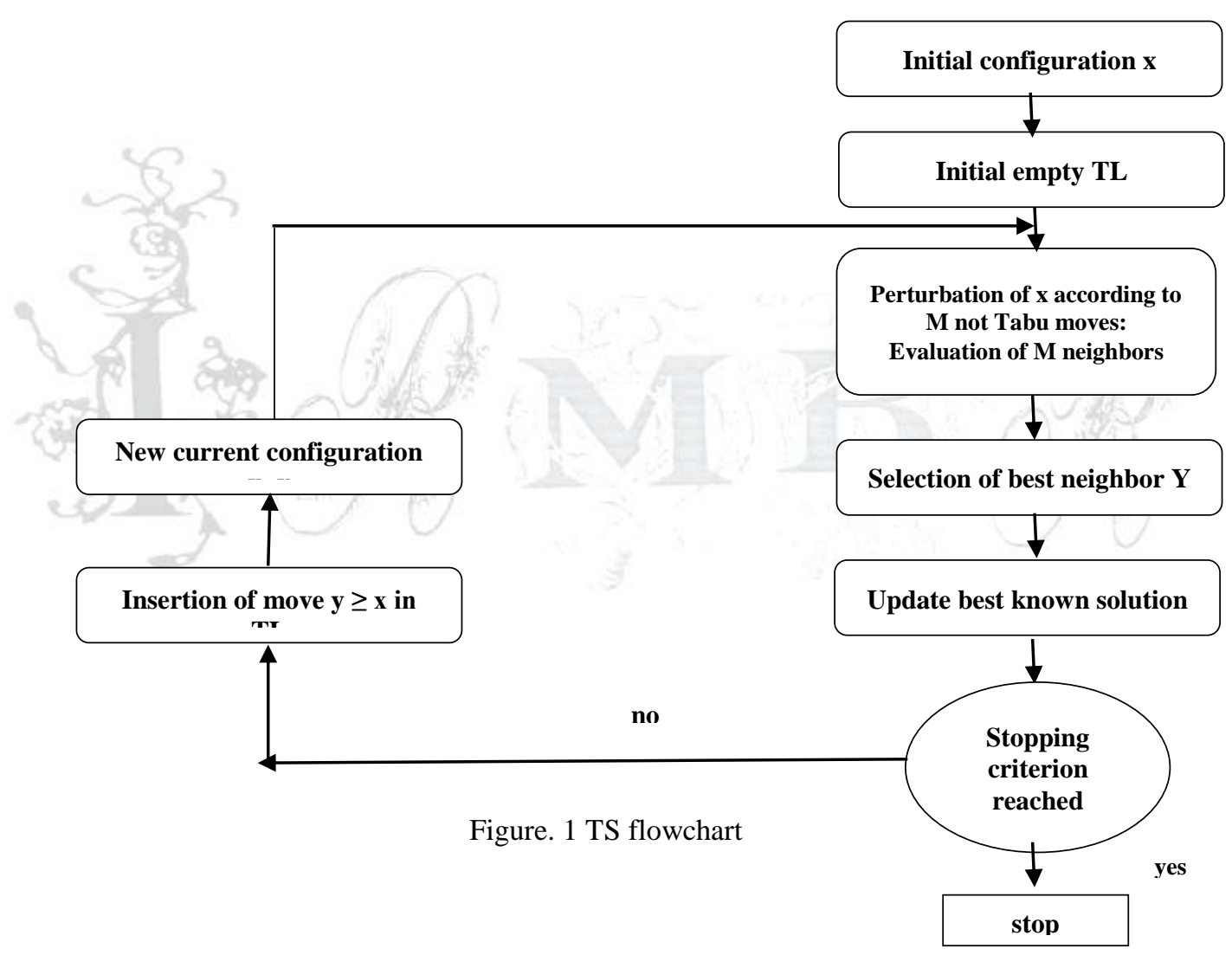

There are many reasons to make TS is good for finding the better solutions for problems. These reasons collected by (Glover \& Laguna, 1997; Chen \& Niu, 2013): as follow

- The ability of this approach to overcome local optimality.

- TS unlike simulated annealing has no stochastic elements.

- This approach combines the aggressiveness of descent methods and the diversity of simulated annealing. 
- $\quad$ TS is better and more success than other metaheuristics to find and improve solutions when there are many solutions.

- TS can be attached within an existing model formulation by adjusting and not changing the system's requirements.

- It is allowing considerable freedom to implement refinements of this method. This method not works under standard way.

- TS has been working successfully to find optimum or near optimum solution to several combinatorial optimisations problems like scheduling, planning and communication...etc.

- Another reason to used TS are simplicity, speed and flexibility of this application to find the solution for problems.

\section{TS Elements}

\section{Initial solution}

Initial solution is the first step of finding best solution in TS algorithm. Without initial solution tabu cannot arrive to the best solution quickly (Chen \& Niu, 2013). Initial solution can be any solution, either feasible or infeasible (Shahvari \& Logendran, 2017b). The initial solution can be generated randomly or in other methods. The quality of final optimal solution (time and cost) depends mainly on the quality of generate initial solution. For example, when the initial solution generated by using FCFs or EDD this will help TS to find the optimal solution and the best solution of objective function. While when algorithm used randomly initial solution may be the optimal solution will be infeasible (Logendran \& Subur, 2004). In this study initial solution generated as follow;

- Create tabu list (TL)

- Tabu list must be equal $\Phi$

- Set tabu list $T L=\Phi$

- Generate initial solution x Randomly.

- If initial solution $x$ less than $\Phi$

- Termination

- If initial solution not less than $\Phi$

- Set current best solution $\mathrm{x}^{*}=\mathrm{x}$

- Evaluate $\mathrm{x}^{*}$

\section{Neighborhood Generation:}

The main philosophy of TS starts throw each iteration of search processes works for finding a good neighborhood solution with focusing on better quality with comparing with current solution, that mean a TS starting with the same way as neighborhood search. The neighborhood of a current solution defined as set of feasible solutions that can be reached by a transition move and the solutions of TS the neighborhood for each case have all solutions which have been explored (Fred Glover \& Laguna, 1997). According to Ponsich and Coello Coello (2013) the neighborhood choice is essential for an efficient implementation of TS and the wide neighborhood work to avoid any losing in optimum solutions and it will be expensive while, a restricted neighborhood will allow saving in time but will possibly prevent the work from reaching the optimum solutions. In this study neighborhood solution generated as follow;

- Being

- $\quad$ Set Tabu list $\mathrm{TL}=\Phi$

- Generate initial solution x randomly

- For utilization of operating room;

- Store all duration of surgery under Ds-surgery 
- Generate all neighborhood solution $\mathrm{x}$ according to Ds-Surgery;

- Make a swap between times who will come from Ds-surgery

- Find the best neighborhood that will give us the best utilization of operating room (x);

- If $\mathrm{f}\left(\mathrm{x}^{\prime}\right)<\mathrm{f}\left(\mathrm{x}^{*}\right)$

- $\mathrm{x}^{*}=\mathrm{x}^{\prime}$

- Else

- Find the best neighborhood solution ( $\left.\mathrm{x}^{\prime}\right)$ that is not tabu list TL

- $(\mathrm{x})=\left(\mathrm{x}^{\prime}\right)$

- $\quad$ End

\section{Tabu List and Tabu Tenure:}

Short term memory employed is the history of recent moves and aims primarily at preventing moving back to these moves, avoiding being trapped at local optima or causing cycling. The most common implementation of the short-term memory is based upon the storage and update of the move attributes that were recently visited. Tabu list are set of solutions obtained from the current solutions by the moves that use some attributes in iteration. This memory forbids solution attribute changes recorded in the short term memory to be reused (Nonobe \& Ibaraki, 1998a). According to Glover, Taillard, and de Werra (1993) TS list designed to ensure that the elimination of cycle of length proportional to the tabu list size provide very good. The tabu list related with size of list, if the size of tabu list is small that mean the search will cycle around a local minimum successfully creating and removing small crosses. In the other hands, if the tabu list size larger, then the moves will allow escape from a local minimum will indeed be performed but the tabu restrictions may render it impossible. Bellanti, Carello, Croce, and Tadei, (2004) showed that the best length of tabu list is six for getting the better results of TS.

Tabu tenure refers to length of tabu list. It is a parameter works to describes how much of the past that should be remembered. It is very important parameter that has a crucial influence over performance but it tedious to tune for each problem under consideration the length of tabu list (Nonobe \& Ibaraki, 1998b). When the tenure size is very large, the solution quality will be decadent. While, when the tenure size is very small, cycling occurrence will be possible, so the best size must be in an intermediate range between these two cases (Niu, Peng, \& ElMekkawy, 2013).

\section{Stopping Criterion}

Glover (1989) showed that there are two ways for making the algorithm stop. First: when there is no improvement between two consecutives. Second: algorithm will stop when it arrives to maximum number of iteration. In this study TS stopped when according to first condition when the researchers find there is no improvement showed in better solution.

\section{Intensification and Diversification}

Intensification based on initiating a return to attractive regions to search them more carefully. Intensification strategies can be applied to stress the search to a more promising region of the solution space, so that the moves to the local optimum are intensified (Barbarosoglu \& Ozgur, 1999 \& Cao, Glover, \& Rego, 2015). while the elite solutions must be recorded in order to examine their immediate neighborhoods, explicit memory is closely related to the implementation of intensification strategies (Fred Glover \& Laguna, 1997). Intensification in TS designed to focus the search more strongly in regions identified by past search history and by current evaluations as likely to harbor good solutions ( $\mathrm{Lu}, \mathrm{Cao}, \&$ Glover, 2017).

The Diversification is the strategy that work to search process to examine unvisited regions and to generate solution that differ in various significant way from solution components that are then fleshed out to produce 
full solution or can rely on modified evaluations as embodied (Cao et al., 2015). It is used to work in the less explored area through forcing moves out of local optimum solution.(Fred Glover, 1989\&Barbarosoglu \& Ozgur, 1999).

\section{Problem Description}

This article focused on Al-Shahid Ghazi Al-Hariri hospital. It is one of the biggest public hospital in Baghdad related with Ministry of health in Iraq. The hospital has 10 surgical departments with 24 operating rooms and 90 surgeons and serviced around 15000 surgeries yearly. Each surgical department have a specific set of operating room. Each set of operating room have a unique and specially type of equipment. This article focusses on neurosurgery department because it is deal with cases come from conflict and because of the high number of injures (head and spin). This department have 3 operating rooms, 10 surgeons and served around 130 cases per month. the hospital work 5 day per week and 8 hours per day. In this study the model is built according to following assumptions:

- Focusing on elective surgery only (with probability of potential interruptions of non-elective surgery).

- $\quad$ Surgeon cannot move to other room or other patient before finishing his work.

- $\quad$ Rooms, staffs and patients must be ready on time and date of scheduling.

- Sterilization and cleaning were calculated within the duration of surgery.

- First operation starts at 8:00am.

- Assigned at least one operation for each operating room per day.

- No overtime accepted.

In this article, works to assigned one patient to one operating room with at least one surgeon at the beginning time of workday to avoid any lack of surgeons and waiting and idle time of patients and make a space for cases coming from conflict.

\section{Model Formulation}

This section elaborates model formulation for this study. The study developed a model related with scheduling operating room. The goal is to maximize utilization of operating rooms. Probability of nonelective surgery or incoming patients that require immediate surgery is also incorporated into the model. The probability represents scenario in al Shahid Ghazi al-Hariri hospital in Baghdad for which scheduling for elective surgeries were occasionally interrupted by incoming war-related incidents victims that require immediate treatments. Follows are details of the model:

\section{Index Set}

Ds: Duration of surgeries; This will be measured in minutes to avoid any losses in time and eliminate idle time and waiting time.

SCs: Surgeon assigned to surgery $s$ : The focus will be on surgeons working in the neurological department.

AScdt: gives the availability of surgeons' $c$ in the day $d$ at period $t$ : it will explain which surgeon available in neurological department will be scheduled the day $d$ at period $t$.

$$
A S c d t=\left\{\begin{array}{l}
1 \text { if surgeon } c \text { is available the day d at the begining of the period } t \\
0 \text { otherwise }
\end{array}\right.
$$




\section{Input Parameters}

S: set of surgeries $\{1 \ldots n s\}:$ It is defined by surgeons and approved by neurosurgery department according to patients waiting list. The surgeries must be scheduled to operating room.

C: set of surgeons $\{1 \ldots . . n c\}$ : The set of surgeons available for operating scheduling.

R: set of rooms $\{1 \ldots . . n r\}$ : The set of room available for operating

D: set of days $\{\mathbf{1} \ldots$ nd $\}$ : The set of day available for scheduling.

T: set of periods $\{1 \ldots n t\}$ : Time available for scheduling.

$\mathbf{T}_{\text {cd }}{ }^{\text {MaxD }}$ : Operating time limits for each surgeon.

Ns: number of elective surgeries to schedule:

Nc: number of surgeons.

$\mathrm{Nr}$ : number of rooms.

Nd: number of days.

Nt: number of unit period.

\subsection{Decision variable:}

$$
\begin{gathered}
X s d r t=\left\{\begin{array}{l}
1 \text { if surgery } s \text { is start on day } d \text { in the room } r \text { at the begining time } t \\
0 \text { otherwise }
\end{array}\right. \\
Y c d r=\left\{\begin{array}{c}
1 \text { if surgeon } c \text { is assigned on the day d at the room } r \\
0 \text { otherwise }
\end{array}\right.
\end{gathered}
$$

\section{Objective Function}

The objective is to maximize the utilization rate of operating room by maximizing the operating room occupation and minimizing the idle time between surgeries while considering probability of receiving incoming patients (non-elective) affected by war-related incidents. The model is formulated as follows:

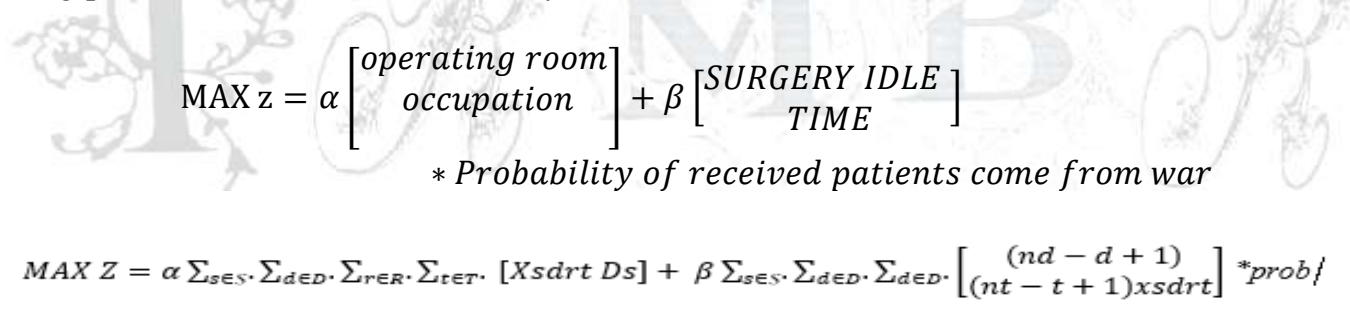

The objective function has three parts. According to Marques, Captivo, and Vaz Pato (2012) the first part concerns the maximization of the occupancy of operating room. the second part of the function allows operations to be planned at the earliest (in terms of periods and also in terms of days) (Bouguerra, Sauvey, $\&$ Sauer, 2015). While the third part demonstrates the probability of receiving cases came from war-related incidents and requiring immediate surgical intervention. (1.15) refers to the probability given from hospital for receiving any cases come from war or related incidents.

According to hospital this percentage was calculated based on statistics which are showing the amount of cases received by the hospital for treatment coming from the battlefield or explosions or any related incident then divided to surgery section department depending on the type of injuries after that add to the elective surgery scheduling. this probability will enter to be normal scheduling.

First and second part of objective function are weighted with $\alpha>\beta$ to reflect the significant importance of operating room occupation with compared with surgery idle time. 


\section{Constraints}

The constraints are as follows:

1. Allocating an operating room for each surgeon per day and not assigning same room to another surgeon on the same day.

$$
\sum_{s \in S} \cdot \sum_{d \in D} \cdot \sum_{r \in R} \cdot \sum_{\substack{t^{\prime}=t-D s+1 \\ t \prime \in T C}}^{t}\left[x s d r t^{\prime} \leq 1, \forall s \in S, d \in D, r \in R, t \in T\right]
$$

2. To ensure surgeon is assigned to only one operating room and can only leave to a second room or second surgery after completion of the first operation. The number Y must be equal to or smaller than 1

$$
\sum_{c \in C} . Y c d t \leq 1, \forall D \in d, \forall T \in t
$$

3. To ensure that each surgeon operates on according to his availability. The number $X$ during duration of surgery must be equal to or smaller than sum of availability of surgeons that are assigned to surgery $\mathrm{S}$.

$$
[X s d r t D s] \leq \sum_{t^{\prime}=t}^{M i n(t+D s-1, n t)} A S S C s d t^{\prime}
$$

4. To ensure that each operating room $r$ in the period $t$ can accept only one patient intervention through the availability of operating room. The number $X$ must be equal to or smaller than 1 .

$$
\sum_{\substack{s \in S . \\ \text { dind }}} X s d r t \leq 1, \forall r \in R, \forall t \in T \text { (5) }
$$

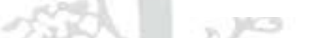

5. The time available for surgery is the same as the actual working time for surgeons (extra work is not allowed). In this constraint want to ensure that the daily operating time is limit for each surgeon.

$$
\sum_{s \in S} D s X s d r t \leq T c d M a x D \forall d \in D, c \in C
$$

6. To find links between decision variables (surgeries and surgeons).

$$
\sum_{s \in S} X s d r t \leq y S C s d t \forall d \in D, r \in R, t \in T
$$

7. To ensure that the variables are in the domain and they are binary variables

$$
\begin{gathered}
(X s d r t) \in\{1,0\}, \forall s \in S, d \in D, r \in R, t \in T \\
Y c d r \in\{1,0\}, \forall c \in C, d \in D, r \in R,
\end{gathered}
$$

\section{Computational Experiments using randomly generated data}

To evaluate the performance and limitations of the proposed model, we randomly generated 50-150 cases in each of the problem sizes tested. The sizes generated are divided in five working day. This is in line with the planning horizon in terms of number of days $(n d)$ and the number of surgeries to be planned $(n s)$. The number of surgeons $(n c)$ are fixed. We consider, for the experiments presented, the case of (3) operating 
rooms available simultaneously for 8 hours period per day. The number of surgeons $(n c)$ is 10 . The availability of surgeons is generated randomly. First, we generate the number of days each surgeon must be present within the operating room. In addition, we require that each surgeon must be in attendance for at least one day during the planning interval. Secondly, we generate number of surgeries for their working days and the number of periods to work per-day. Table 1 depicts problem size, number of variables and randomly generated data

Table1. Problem size

\begin{tabular}{||c||c||c||c||c||c||c||}
\hline No. & $\begin{array}{c}\text { Number of } \\
\text { day (nd) }\end{array}$ & $\begin{array}{c}\text { Number of } \\
\text { surgeon }(\mathrm{nc})\end{array}$ & $\begin{array}{c}\text { Number of } \\
\text { surgery (ns) }\end{array}$ & $\begin{array}{c}\text { Number of } \\
\text { room (Nr) }\end{array}$ & $\begin{array}{c}\text { Number of } \\
\text { time (T) }\end{array}$ & Variables \\
\hline \hline 1 & 1 & 10 & 50 & 3 & 8 & 1200 \\
\hline \hline 2 & 2 & 10 & 70 & 3 & 8 & 3360 \\
\hline \hline 3 & 3 & 10 & 90 & 3 & 8 & 6480 \\
\hline \hline 4 & 4 & 10 & 120 & 3 & 8 & 11520 \\
\hline \hline 5 & 5 & 10 & 150 & 3 & 8 & 18000 \\
\hline
\end{tabular}

The experiment was executed on a PC with Intel (R) core (TM) i3-2328M, CPU 2.20 GHz and 2.00GB RAM and solved using Microsoft Visual Basic.Net 2012. Table 2 shows summary of the computational results:

\section{Computational experiments using real data from Al-Shahid Ghazi Al-Hariri Hospital}

This section will be testing the model with data was collected from Al-Shahid Ghazi Al-Hariri hospital in Baghdad with 5 of work days per week and 20 days per month, number of weekly workhours, number of operating rooms available and number of surgeons present in the Neurosurgery department in problem description and comparing these results with another results used same model but solved by MILP Table 2 shows the utilization of operating room for week number one as follow:

Table 2. computational result week one with real data

\begin{tabular}{|c|c|c|c|c|c|c|c|c|}
\hline \multirow[b]{2}{*}{ No } & \multirow[b]{2}{*}{$\begin{array}{l}\text { Number of } \\
\text { day (nd) }\end{array}$} & \multirow[b]{2}{*}{$\begin{array}{c}\text { Number of } \\
\text { surgeon (nc) }\end{array}$} & \multirow[b]{2}{*}{$\begin{array}{c}\text { Number of } \\
\text { surgery (ns) }\end{array}$} & \multicolumn{2}{|c|}{ Mathematical model } & \multicolumn{3}{|c|}{ TS } \\
\hline & & & & OPT $^{*}$ & $\begin{array}{l}\text { Calculated } \\
\text { time in } \\
\text { second }\end{array}$ & $\begin{array}{l}\text { Best } \\
\text { sol. }\end{array}$ & $\begin{array}{c}\text { Calculated } \\
\text { time in } \\
\text { second }\end{array}$ & /Gap/ \\
\hline 1 & 1 & 10 & 6 & 1.00 & 160 & 0.93 & 94 & $7 \%$ \\
\hline 2 & 2 & 10 & 6 & 0.95 & 359 & 0.89 & 55 & $6 \%$ \\
\hline 3 & 3 & 10 & 6 & 0.88 & 843 & 0.77 & 24 & $13 \%$ \\
\hline 4 & 4 & 10 & 6 & 0.75 & 219 & 0.71 & 10 & $5 \%$ \\
\hline$\overline{5}$ & $\overline{5}$ & 10 & $\overline{6}$ & 0.63 & $\overline{452}$ & 0.59 & 10 & $6 \%$ \\
\hline & & & & & & \multicolumn{3}{|c|}{ Mean rounded value } \\
\hline & & & & & & \multicolumn{2}{|c|}{38.6 second } & $8.4 \%$ \\
\hline
\end{tabular}

OPT = optimum solution obtained by mathematical model in chapter four.

Gap $\left.=\frac{\text { best sol }-O P T}{O P T} * 100\right)$

Mean rounded value $=\frac{\text { sum of estmatied times value }}{\text { number of elements }}$

From the table above, we can see that the highest utilization in TS was in the first day with 0.93 and the lowest utilization was in the fifth day with (0.59) and when comparing the average gap between optimal 
solution in MILP model and best solution in TS it was (8.4\%) while the average time to arrive to objective solution was only (38.6) second. That means TS can find the nearest optimal solution and it take a few seconds. In the same way we calculated the utilization of operating rooms for week two to four as follow

Table 3. computational result with real data weeks 2-4

\begin{tabular}{|c|c|c|c|c|c|c|c|c|c|c|c|c|c|c|c|c|c|}
\hline \multirow[t]{2}{*}{ nd } & \multirow[t]{2}{*}{ nc } & \multirow[t]{2}{*}{ Ns } & \multicolumn{2}{|c|}{$\begin{array}{l}\text { MILP } \\
\text { model } \\
\text { Week2 }\end{array}$} & \multicolumn{3}{|c|}{$\begin{array}{c}\text { TS } \\
\text { Week2 }\end{array}$} & \multicolumn{2}{|c|}{$\begin{array}{l}\text { MILP } \\
\text { model } \\
\text { week3 }\end{array}$} & \multicolumn{3}{|c|}{ TS Week3 } & \multicolumn{2}{|c|}{$\begin{array}{l}\text { MILP } \\
\text { model } \\
\text { week4 }\end{array}$} & \multicolumn{3}{|c|}{ TS Week4 } \\
\hline & & & $\begin{array}{l}\mathbf{O P} \\
\mathbf{T}^{*}\end{array}$ & $\begin{array}{l}\text { ET } \\
\text { Sec }\end{array}$ & $\begin{array}{l}\text { Best } \\
\text { sol." }\end{array}$ & $\begin{array}{l}\text { ET } \\
\text { Sec }\end{array}$ & /Gap/ & $\begin{array}{c}\text { OP } \\
T\end{array}$ & $\overline{E t}$ & $\begin{array}{c}\text { Best } \\
\text { sol }\end{array}$ & $\mathbf{E t}$ & Gap & $\begin{array}{c}\text { OP } \\
T\end{array}$ & Et & $\begin{array}{c}\text { Best } \\
\text { sol }\end{array}$ & $\overline{E t}$ & Gap \\
\hline 1 & 10 & 6 & 1.07 & 582 & 1.04 & 109 & $3 \%$ & 1.08 & 687 & 1.05 & 94 & $3 \%$ & 1.10 & 515 & 1.05 & 93 & $5 \%$ \\
\hline 2 & 10 & 6 & 0.97 & 145 & 0.83 & 93 & $14 \%$ & 0.97 & 250 & 0.92 & 78 & $5 \%$ & 0.97 & 1110 & 0.93 & 86 & $4 \%$ \\
\hline 3 & 10 & 6 & 0.86 & 629 & 0.81 & 92 & $6 \%$ & 0.85 & 875 & 0.81 & 109 & $5 \%$ & 0.84 & 265 & 0.81 & 109 & $4 \%$ \\
\hline 4 & 10 & 6 & 0.70 & 254 & $\mathbf{0 . 7 0}$ & 35 & 0\% & 0.74 & 531 & 0.71 & 86 & $4 \%$ & 0.72 & 578 & 0.70 & 37 & $3 \%$ \\
\hline \multirow[t]{3}{*}{5} & 10 & $\bar{~} 6$ & 0.63 & 580 & 0.60 & 17 & $5 \%$ & 0.62 & 141 & 0.60 & 34 & $3 \%$ & 0.61 & 240 & 0.59 & 48 & $3 \%$ \\
\hline & & & \multicolumn{5}{|c|}{ Mean rounded value } & \multicolumn{5}{|c|}{ Mean rounded value } & \multicolumn{5}{|c|}{ Mean rounded value } \\
\hline & & & \multicolumn{3}{|c|}{69.2 second } & & $6 \%$ & & & \multicolumn{2}{|c|}{$\begin{array}{c}80.2 \\
\text { second }\end{array}$} & $4 \%$ & \multicolumn{2}{|c|}{74.6 second } & \multicolumn{3}{|c|}{$4 \%$} \\
\hline
\end{tabular}

Table 3 depicts the utilization in operating room for week (2-4). From the table above we can see that on the first day of the week full utilization had been achieved for all weeks. The high utilization in this day came from the minimization of the waiting time for patients, minmize the idle time for surgeons and maximizing the occupation of operating room through high response to all patient under scheduling plus the cases war-related incidents. We can see that the utilization was exceeds than $100 \%$ in the first day too and this is possible when the reasons of this higher percentage came because the surgeons cant leave operating room without finished the last operation.

That means the surgeons will work more than 8 hours in that day. Because some time the surgeons was plan that the operation will take four hours but after starts it take more than planned. In this case surgeons cant stop before finish. In the other hand, we can see that the gap between using MILP and TS methods in the first day was accaptance too it was between (3\% to $5 \%)$.

In general TS model showed that we can depand on this model comaring with MILP and the results will be accaptance too as we can see from table 3 that the mean rounded value for week 2 the Gap between MILP and TS was $6 \%$ wile the average rounded time value for TS was only 69.2 seconds comparing with MILP it was 438 second. And for week 3 the gap was $4 \%$ and the mean rounded value was 80.2 seconds compariong with MILP the mean rounded value was 497 seconds, and for week 4 the gap between TS and MILP was $4 \%$ while the mean rounded value was 74.6 seconds comaring with MILP it was 342 seconds.

For all results above we can see that TS arrived to the article objective by increasing the utilization of operating rooms in Al-Shahid Ghazi Al-hariri Hospital in Iraq with used less time. And that confirm that our model work to maximize the occupation of operating room and minimize the idle time between surgeries and received other cases came from conflict and enter it with elective surgery. Figure1. shows comparison between utilization results between MILP model and TS model 


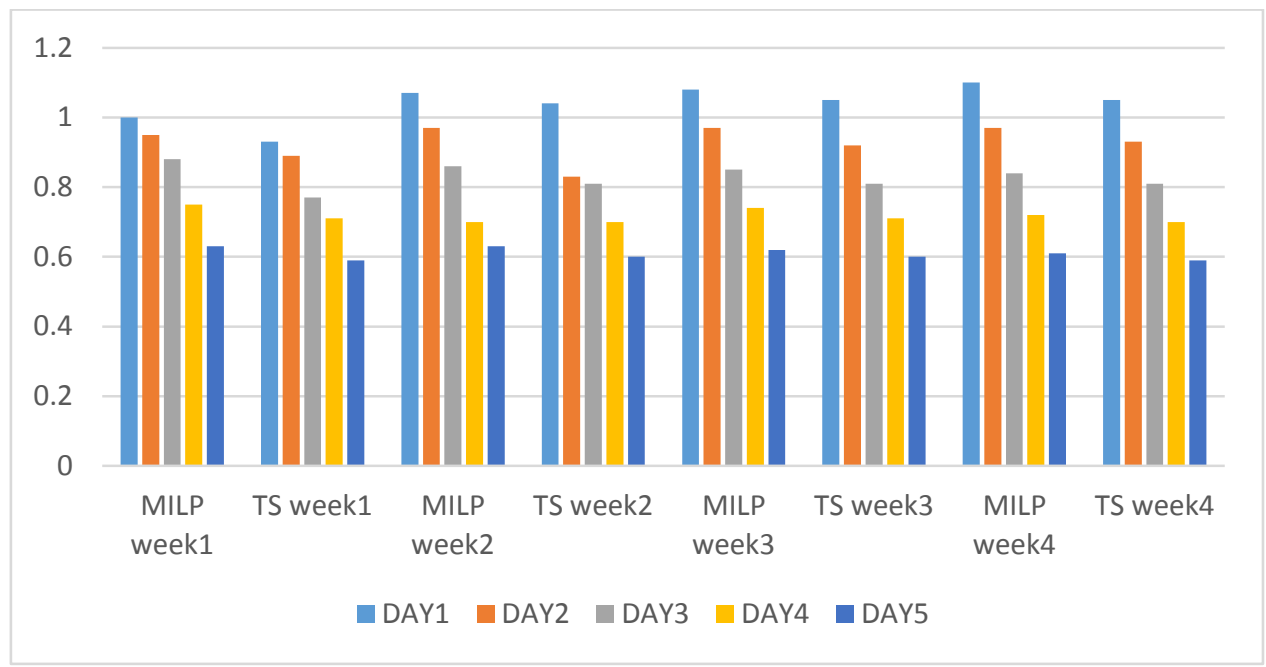

Figure2. MILP results comparing with TS results

\section{Gap Analysis}

For gaps figure 3 show the gap between days during four weeks. We can see that the gaps between utilizations in optimal and best solution are wavering (up and down) between (14\%) in the second day of week two and $(0 \%)$ in the fourth day from the same week. For first week the gap was in minimum in fourth day with $(5 \%)$ between the optimal solution and best solution, while the maximum gap was in third day with (13\%). In week two the minimum gap was in the fourth day $(0 \%)$ because the optimal solution was equal the best solution in this day while the maximum gap was in the second day (14\%). In the third week the minimum gap was in the first and fifth day with (3\%) while the maximum gap was in the second and third day with $(5 \%)$. For week number four the minimum gap between optimal solution and best solution was in days fourth and fifth days with (3\%) while the maximum gap was in the first day with (5\%). For higher gaps $(13 \%)$ and $(14 \%)$ tabu search stop his iteration when he felt that the best solution couldn't improvement and no need for increase the iteration and increase the computational time as all solution are similar. So, the gap be higher than other gaps in other weeks and days. But in general, the average gap for all weeks was less than $10 \%$ so, the gaps were acceptable.

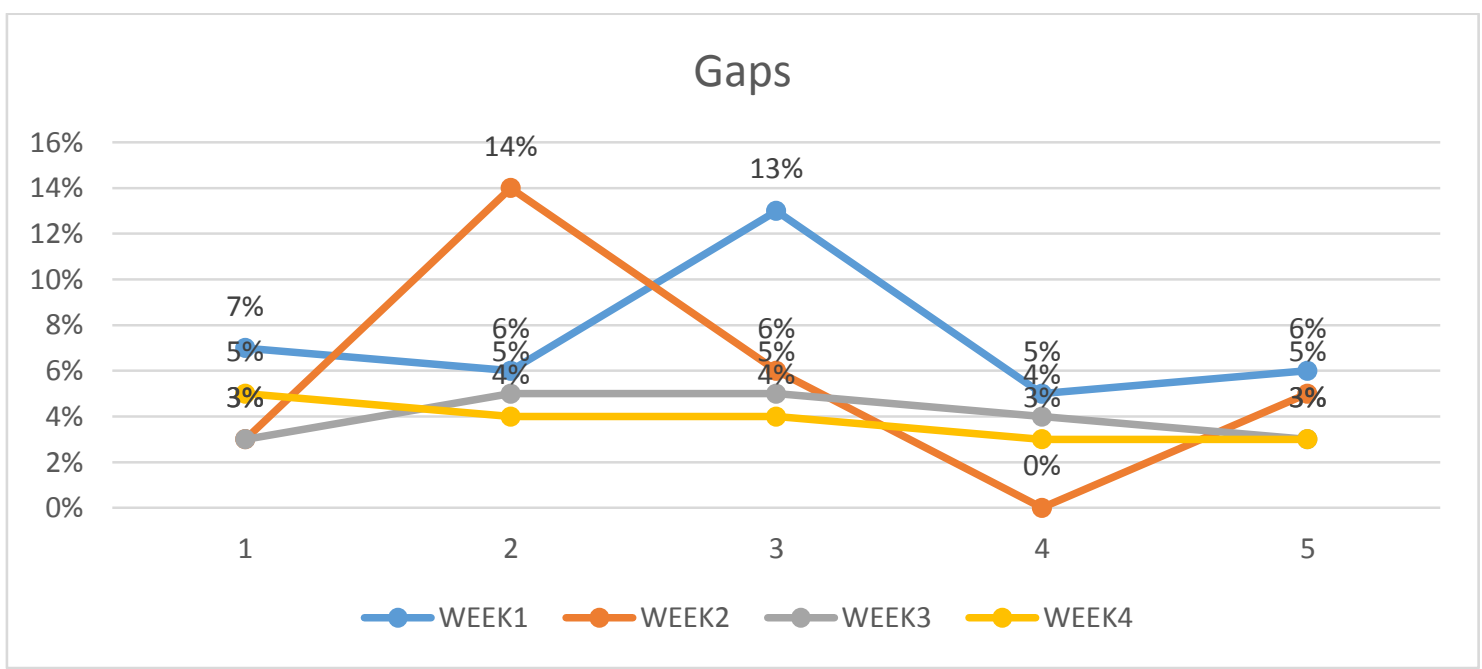

Figure 3. Gaps between optimal solution and best solution of week 1-4 


\section{Conclusion}

This research intends to find ways of utilizing operating room availability of Al-Shahid Ghazi Al-Hariri hospital by using metaheuristic approach $(T S)$ and comparing the results with other taken from a mathematical programming method. The focus was on elective surgery of the Neurosurgery department with probability of interruptions of non-elective surgery due to war-related incidents. (TS) model was developed to address this issue. The model aims to maximize utilization rate of operating room to minimizing the idle time between surgeries and do a comparing between using (TS) model and (MILP) model to solve problem related to delay in time and increasing the utilization of operating room. The workability of the model was then tested. The computational experiments showed that the model is workable and feasible. Nevertheless, the time was taken to solve problem size was less comparing with longer time when we used mathematical model. Hence, the usage of heuristics method was a very good choice.

Future research is needed to determine the near best solutions for scheduling in operating room using another metaheuristics method like Genetic algorithm or ant colony ...etc. to compare the results with TS results and decide which metaheuristic is better than other to make the model faster and more practical. Overall, the proposed model has managed to demonstrate its potential usability and capability. It may also be beneficial to hospital administrators or regulatory bodies particularly in volatile country where hospitals are dealing with victims from war-related incidents, and where scheduling for elective surgery often interrupted by non-elective surgery. On the other hand, use the same model on the other surgical department in Al-Shahid Ghazi Al-Hariri hospital and compare the results of the hospital departments and compare them with the results of neurosurgery department and give observations to the management of the hospital for applying this model in their work.

\section{References}

Amaral Armentano, V., \& Rigão Scrich, C. (2000). Tabu search for minimizing total tardiness in a job shop. International Journal of Production Economics, 63(2), 131-140. https://doi.org/10.1016/S09255273(99)00014-6

Aringhieri, R., Landa, P., Soriano, P., Tànfani, E., \& Testi, A. (2015). A two level metaheuristic for the operating room scheduling and assignment problem. Computers \& Operations Research, 54, 21-34. https://doi.org/10.1016/j.cor.2014.08.014

Barbarosoglu, G., \& Ozgur, D. (1999a). A tabu search algorithm for the vehicle routing problem. Computers \& Operations Research, 26(3), 255-270. https://doi.org/10.1016/S0305-0548(98)00047-1

Barbarosoglu, G., \& Ozgur, D. (1999b). A tabu search algorithm for the vehicle routing problem. Computers \& Operations Research, 26(3), 255-270. https://doi.org/10.1016/S0305-0548(98)00047-1

Bellanti, F., Carello, G., Croce, F. Della, \& Tadei, R. (2004). A greedy-based neighborhood search approach to a nurse rostering problem, 153, 28-40. https://doi.org/10.1016/S0377-2217(03)00096-1

Bouguerra, A., Sauvey, C., \& Sauer, N. (2015). Mathematical model for maximizing operating rooms utilization. IFAC-PapersOnLine, 48(3), 118-123. https://doi.org/10.1016/j.ifacol.2015.06.068

Cao, B. Y., Glover, F., \& Rego, C. (2015). A tabu search algorithm for cohesive clustering problems. Journal of Heuristics, 21(4), 457-477. https://doi.org/10.1007/s10732-015-9285-2

Cardoen, B., Demeulemeester, E., \& Beliën, J. (2010). Operating room planning and scheduling: A literature review. European Journal of Operational Research, 201(3), 921-932. https://doi.org/10.1016/j.ejor.2009.04.011

Chen, M., \& Niu, H. (2013a). Optimizing schedules of rail train circulations by tabu search algorithm. Mathematical Problems in Engineering, 2013(Article ID 102346,), 1-8. https://doi.org/10.1155/2013/102346

Chen, M., \& Niu, H. (2013b). Optimizing schedules of rail train circulations by tabu search algorithm. Mathematical Problems in Engineering, 2013(Article ID 102346,), 1-8. https://doi.org/10.1155/2013/102346 
Cordeau, J.-F., \& Laporte, G. (2005). A tabu search heuristics for the vehicle routing problem. Metaheuristic Optimization via Memory and Evolution, 40, 145-163. https://doi.org/10.1007/0-38723667-8_6

Cordeau, J.-F., Laporte, G., \& Mercier, a. (2001). A unified tabu search heuristic for vehicle routing problems with time windows. Journal of the Operational Research Society, 52(8), 928-936. https://doi.org/10.1057/palgrave.jors.2601163

Cordeau, J.-F., \& Maischberger, M. (2012). A parallel iterated tabu search heuristic for vehicle routing problems. Computers \& Operations Research. https://doi.org/10.1016/j.cor.2011.09.021

de Werra, D., \& Hertz, a. (1989). Tabu search techniques. Operations-Research-Spektrum, 11(3), 131141. https://doi.org/10.1007/BF01720782

Demeester, P., Souffriau, W., De Causmaecker, P., \& Vanden Berghe, G. (2010). A hybrid tabu search algorithm for automatically assigning patients to beds. Artificial Intelligence in Medicine, 48(1), 6170. https://doi.org/10.1016/j.artmed.2009.09.001

Diaz, J., \& Fernández, E. (2001). A tabu search heuristic for the generalized assignment problem. European Journal of Operational Research, 132, 22-38. https://doi.org/10.1016/S03772217(00)00108-9

Dowsland, K. a. (1998). Nurse scheduling with tabu search and strategic oscillation. European Journal of Operational Research, 106(2-3), 393-407. https://doi.org/10.1016/S0377-2217(97)00281-6

Glover, F. (1986). Future paths for integer programming and links to artificial intelligence. Computers and Operations Research, 13(5), 533-549. https://doi.org/10.1016/0305-0548(86)90048-1

Glover, F. (1989a). Tabu Search - Part I. ORSA Journal on Computing, 2 1(3), 4-32. https://doi.org/10.1287/ijoc.2.1.4

Glover, F. (1989b). Tabu Search - Part I. ORSA Journal on Computing, 2 1(3), 4-32. https://doi.org/10.1287/ijoc.2.1.4

Glover, F., \& Laguna, M. (1997). Tabu search. Kluwer Academic Publishers, Boston,.

Glover, F., Taillard, E., \& de Werra, D. (1993). A user's guide to tabu search. Annals of Operations Research, 41(1), 1-28. https://doi.org/10.1007/BF02078647

Hansen, P., \& Jaumard, B. (1990). Algorithms for the maximum satisfiability problem. Computing, 44(4), 279-303. https://doi.org/10.1007/BF02241270

Lehtonen, J.-M., Torkki, P., Peltokorpi, A., \& Moilanen, T. (2013). Increasing operating room productivity by duration categories and a newsvendor model. International Journal of Health Care Quality Assurance, 26(2), 80-92. Retrieved from http://dx.doi.org/10.1108/09526861311297307

Lim, G. J., Mobasher, A., Bard, J. F., \& Najjarbashi, A. (2016). Nurse Scheduling with Lunch Break Assignments in Operating Suites. Operations Research for Health Care. https://doi.org/10.1016/j.orhc.2016.07.001

Logendran, R., \& Subur, F. (2004). Unrelated parallel machine scheduling with job splitting. IIE Transactions, 36(4), 359-372. https://doi.org/10.1080/07408170490279598

Lu, Y., Cao, B., \& Glover, F. (2017). A Tabu Search based clustering algorithm and its parallel implementation on Spark.

Marques, I., Captivo, M. E., \& Vaz Pato, M. (2012). An integer programming approach to elective surgery scheduling. OR Spectrum, 34(2), 407-427. https://doi.org/10.1007/s00291-011-0279-7

Niu, Q., Peng, Q., \& ElMekkawy, T. Y. (2013). Improvement in the operating room efficiency using Tabu search in simulation. Business Process Management Journal, 19(5), 799-818. https://doi.org/http://dx.doi.org/10.1108/BPMJ-Nov-2011-0081

Nonobe, K., \& Ibaraki, T. (1998a). A Tabu Search Approach to the Constraint Satisfaction Problem as a General Problem Solver. European Journal of Operational Research, 106(2-3), 599-623. https://doi.org/10.1016/S0377-2217(97)00294-4

Nonobe, K., \& Ibaraki, T. (1998b). A Tabu Search Approach to the Constraint Satisfaction Problem as a General Problem Solver. European Journal of Operational Research, 106(2-3), 599-623. https://doi.org/10.1016/S0377-2217(97)00294-4

Nowicki, E., \& Smutnicki, C. (2005). An advanced tabu search algorithm for the job shop problem. Journal of Scheduling, 8(2), 145-159. https://doi.org/10.1007/s10951-005-6364-5 
Ponsich, A., \& Coello Coello, C. A. (2013a). A hybrid Differential Evolution-Tabu Search algorithm for the solution of Job-Shop Scheduling Problems. Applied Soft Computing, 13(1), 462-474. https://doi.org/10.1016/j.asoc.2012.07.034

Ponsich, A., \& Coello Coello, C. A. (2013b). A hybrid Differential Evolution-Tabu Search algorithm for the solution of Job-Shop Scheduling Problems. Applied Soft Computing, 13(1), 462-474. https://doi.org/10.1016/j.asoc.2012.07.034

Saremi, A., Jula, P., Elmekkawy, T., \& Wang, G. G. (2013). Appointment scheduling of outpatient surgical services in a multistage operating room department. International Journal of Production Economics, 141(2), 646-658. https://doi.org/10.1016/j.ijpe.2012.10.004

Shahvari, O., \& Logendran, R. (2017a). An Enhanced tabu search algorithm to minimize a bi-criteria objective in batching and scheduling problems on unrelated-parallel machines with desired lower bounds on batch sizes. Computers and Operations Research, 77, 154-176. https://doi.org/10.1016/j.cor.2016.07.021

Shahvari, O., \& Logendran, R. (2017b). An Enhanced tabu search algorithm to minimize a bi-criteria objective in batching and scheduling problems on unrelated-parallel machines with desired lower bounds on batch sizes. Computers and Operations Research, 77, 154-176. https://doi.org/10.1016/j.cor.2016.07.021

Soon, T. H., \& School, R. D. S. (1997). Intelligent simulation-based scheduling of workcells: an approach. Integrated Manufacturing Systems, 8(1), 6-23. https://doi.org/10.1108/09576069710158754

Thamilselvan, R., \& Balasubramanie, P. (2009). Integrating Genetic Algorithm, Tabu Search Approach for Job Shop Scheduling. Arxiv Preprint, 2(1), 6. Retrieved from http://arxiv.org/abs/0906.5070

Xu, L., Yanpeng, L., \& Xuan, J. (2013). Based on Tabu Search and Particle Swarm Optimization algorithms solving Job shop Scheduling optimization problems, 1-3. https://doi.org/10.1109/ICDMA.2013.78 